\title{
Relationship Between Mentor Retention and the Role of Personality: A Descriptive-Analytical Study
}

This article was published in the following Dove Press journal:

Journal of Multidisciplinary Healthcare

\author{
Nastaran Maghbouli (D) ${ }^{1,2}$ \\ Mahboobeh Khabaz \\ Mafinejad (iD ${ }^{3}$ \\ Saeed Pourhassan (iD ${ }^{4}$ \\ 'Department of Physical Medicine and \\ Rehabilitation, School of Medicine, \\ Tehran University of Medical Sciences, \\ Tehran, Iran; ${ }^{2}$ Mentoring Office, Faculty \\ Education Deputy, School of Medicine, \\ Tehran University of Medical Sciences, \\ Tehran, Iran; ${ }^{3}$ Department of Medical \\ Education, Education Development \\ Center (EDC), Health Professions \\ Education Research Center, Tehran \\ University of Medical Sciences, Tehran, \\ Iran; ${ }^{4}$ Department of Internal Medicine, \\ Shariati Hospital, Tehran University of \\ Medical Sciences, Tehran, Iran
}

Purpose: According to the nature of mentoring, losing mentors reduces a program's capacity and causes a waste of resources to recruit, screen, and train new mentors. The purpose of this study was to assess the relationship between personality traits and retention intention among mentors and also the duration of mentor retention.

Methods: This is a descriptive-analytical study conducted at Tehran University of Medical Sciences. To assess relationship of mentor retention with their personality traits, one hundred forty mentors were surveyed. Participants were surveyed using the Temperament and Character Inventory. We used independent $t$-test, Pearson correlation and regression analysis with SPSS version 20.

Results: The response rate was $70 \%$; of 98 respondents, $30.6 \%$ were male. There was a significant mean difference for self-transcendence and self-directedness traits with the mentors' intention to retention, respectively $(\mathrm{t}=1.672, \mathrm{p}=0.046$ and $\mathrm{t}=2.761, \mathrm{p}=0.011)$. Furthermore, novelty seeking and self-directedness traits significantly predicted the mentor's intention to retention [OR=5.583 (1.656-18.826), 5.284 (1.310-21.309); respectively].

Conclusion: According to findings, the improved mentor's attitudes to retain in program may, therefore, be explained by an increase in mentors' self-directedness and novelty-seeking traits. Policy maker and educational managers should renew the process of recruitment of mentors and introduce supportive strategies every year to retain mentors, which can contribute to their retention.

Keywords: traits, mentoring, personality, retention, temperament
Correspondence: Saeed Pourhassan Department of Internal Medicine, Shariati Hospital, Tehran University of Medical Sciences, Tehran, Iran

Email Saeed.Pourhassan@gmail.com

\section{Introduction}

Mentoring is conducted to smooth the transition of fresh medical students to university. Although the role of mentoring as an effective factor in professional improvements is considerable, most medical schools face some challenges related to mentor retention. ${ }^{1}$ Mentoring not only benefits mentors by providing them with the opportunity to learn, increase job performance, enjoy a supportive network, and personal satisfaction and development, ${ }^{2,3}$ but it also reduces the potential costs including time and energy drain, and failed relationships that may negatively impact participants' judgments resulting in mentor loss for the system. ${ }^{4}$ The evidence clearly shows that mentored students can acquire remarkable outcomes compared with non-mentored students. ${ }^{5}$ Losing mentors, especially experienced and trained ones, reduces a program's capacity and results in wasting of time and resources to recruit, screen, and train new mentors.

To attract the best talents, an organization needs to be viewed as the best place to work. ${ }^{6}$ This is considered to be necessary but not by all means sufficient. While most of the supportive strategies for mentor retention are environment-dependent, 
some are personality-based. ${ }^{7}$ Even adherence to organization rules for a successful relationship is somewhat associated with the mentor's personality. ${ }^{8}$ There are underlying theories for conducting mentoring program and assessing its effectiveness on mentors. In our study, we have tried to use Trait-factor theory goes back as far as the early 1900s. ${ }^{9}$ Based on this theory, different personalities fit with different roles in conducting activities. One of the implication of this theory for mentoring program is ensuring that mentors can have the opportunity to reflect on their own personalities and compare these insights in their mentorship participation. [Figure 1]

In current literature, personality traits such as high openness to experience, agreeableness, high empathy and helpfulness and high novelty-seeking are introduced as desirable characteristics for a successful relationship. ${ }^{10-12}$ Maghbouli et al found that mentors who are high in novelty-seeking in particular may have several characteristics that make them effective in mentor-mentee relationship and mentee satisfaction, ${ }^{10}$ while Bozionelos reported a limited role for the personality of the mentor in providing mentoring. ${ }^{13}$

Nowadays, mentoring is becoming an essential component of medical education all around the world. Although there is a growing effort for incorporating mentoring program in medical education, what the effects of implementation program on mentors remain to be debated. Furthermore,
Iranian literature indicate that more students are interested in mentoring for medical education curricula in this country. ${ }^{14-16}$ Taqavi et al findings in 2018 showed that mentoring is more widespread than it used to be. ${ }^{17}$

Although many studies have reported the effects of mentor personality in initiation and maintenance of mentor-mentee relationship, ${ }^{12}$ there have been few studies on personality traits conducive to the increased retention of mentors. Furthermore, little details have been offered on the effect of screening and recruiting processes on the retention of mentors. The aim of this study was to evaluate the relationship between personality traits and retention intention among mentors and also the duration of mentor retention at Tehran University of Medical Sciences (TUMS).

\section{Materials and Methods}

\section{Sample}

This was a descriptive-analytical study carried out from January to March 2018. One hundred forty mentors of TUMS participated in this study, with the mean age of $24.56+1.68$.

\section{Mentoring Program}

The medical school at TUMS in Iran implemented a mentoring program to improve its educational climate for freshmen medical students. A peer mentoring program

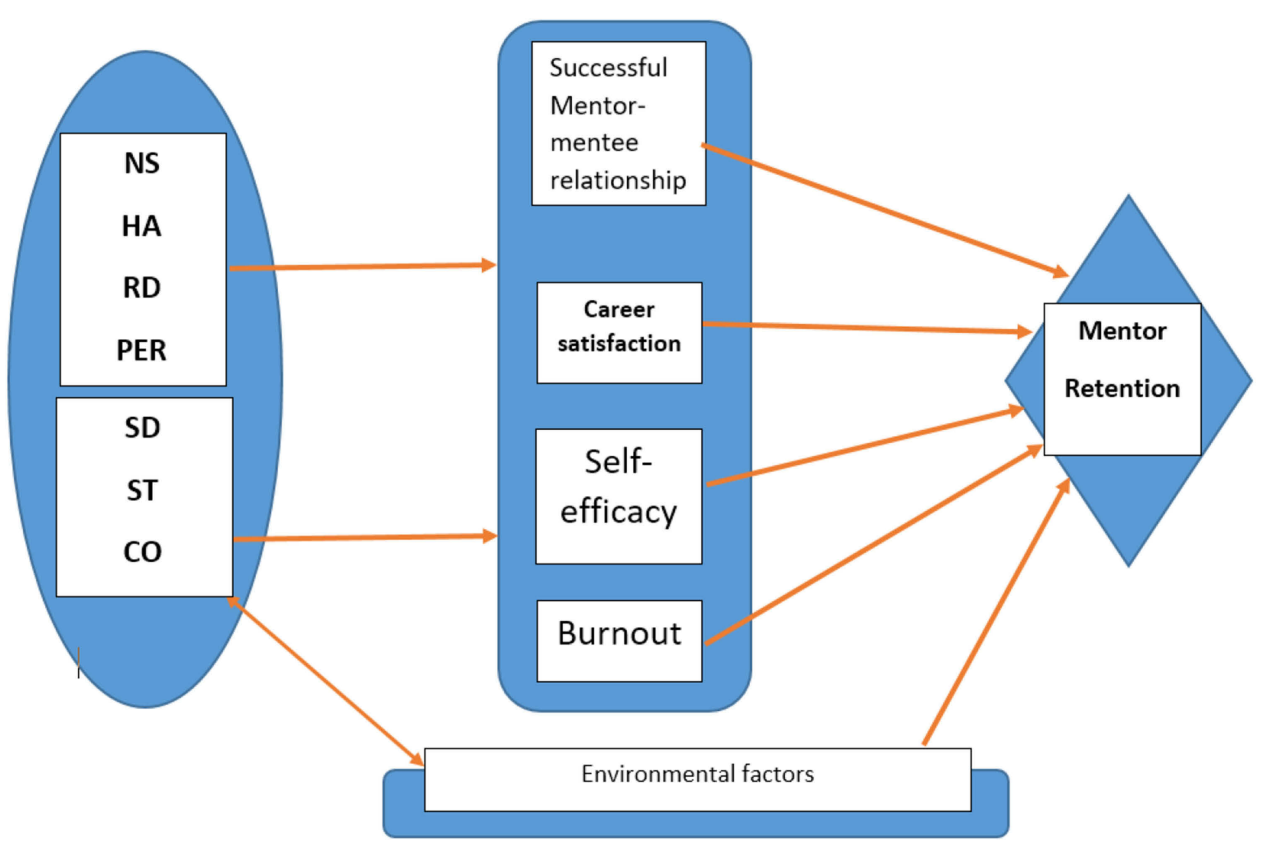

Figure I Mentor Retention Conceptual Map. 
was conducted to assist first-year medical students from 2011 to 2018. Three groups of students including mentors, mentees, and coordination group members are engaged in TUMS mentoring program.

First, mentors who were selected from medical students ranging from 3rd year to clinical residents. Students are eligible to apply if they are in good academic and professional condition. The mentor application process includes evaluation of past history of teaching roles, and a self-assessment of mentorship skills. Senior mentors make recommendations based on their knowledge of each new applicant mentors. Final selection is made by a committee of faculty members and experienced mentors. The committee did their best to choose a representative sample of students with diversity. One hundred and forty medical students participated in the program as mentors. All mentors were trained on the concept of mentoring, communication skills, program rules and expectations and the support by the faculty. Mentors were also expected to make themselves available to their mentees on peer mentoring basis. After each mentor-mentee meeting, mentors were called for session assessment, which is used to improve future meetings effectiveness. Regular seasonal inter-mentor sessions were held so that the mentors could exchange ideas and share their experiences about their mentor-mentee relationships.

Second, mentors as coordination group members including a group of 4-6 volunteers. Despite being mentor, coordination group members decide about challenges of program to find solutions. In addition, they monitor mentor-mentee relationships weekly and give feedback on mentors' performance. Regular weekly coordination group meetings were held for evaluation of mentormentee challenges and making decisions for upcoming events. At the end of the year, evaluation surveys were developed to assess program effectiveness and to direct program improvements by coordination group. These members selection process is the same as mentors in which managerial background and skills are of importance. There were no more incentives than mentors for coordination group members.

Third, first-year medical students as mentees who could register voluntarily for the program by filling out registration forms, after having been briefed about the program during the first week. They were assigned to mentors based on gender, ethnicity, living place and scientific background. Mentees received mentorship through one-on-one meetings predominantly face to face. There is also referral system for mentees with more complicated problems.

\section{Procedures}

All questionnaires were emailed to participants with a link to complete the survey electronically. They were asked to complete the questionnaire voluntarily in their own time and return when they had completed it with one week limitation to return with two reminders. Tehran University of Medical Sciences institutional review board approved this study IR. TUMS.REC (96-02-76-32616). Students received a full explanation before participation, which was voluntary, and anonymity was guaranteed. Written informed consent was obtained from all participants.

\section{Measurements}

The Temperament and Character Inventory (TCI) is a selfreport scale, which measures four temperament and three character traits of Cloninger's psychological model of personality. ${ }^{18}$ We use the TCI a more precise and comprehensive version of the TPQ, for assessing temperament and character. The questionnaire targets four aspects of temperament [ie, novelty-seeking (NS), harm avoidance (HA), reward dependence (RD), and persistence $(\mathrm{P})]$ and three aspects of character [ie, self-directedness (SD), cooperativeness (C), and self-transcendence (ST)]. NS, HA, RD, P, SD, C, and ST scales, has 3 to 5 subscales, except for $\mathrm{P}$, with 1 subscale. ${ }^{19}$ TCI scale has 2 versions, original version with 240 items and revised version with 125 items. Although original versions items are rated with a 2-point scale ("yes" or "no"); there are some ratings for revised version based on Likert scale. ${ }^{20,21}$ Given that evidence suggest that the Likert scale is superior to dichotomous scale in terms of reliability, the scores of temperament and character traits of mentors were determined by temperament and character inventory with 125 items (TCI-125) expressed as a Likert scale from (absolutely false) to (absolutely true). The validity and reliability of the Persian version of the TCI were previously assessed and shown to be highly reliable. ${ }^{20}$ Furthermore, study questionnaire consisted demographic (age, gender) and retention-related information. Coordination group membership and intention to retention next year were asked in yes/no question form. The number of years of participation as a mentor in the program was used as an indicator for evaluating "mentor retention" using open-ended question. All questionnaires were emailed to participants with a link to complete the survey electronically. They were asked to 
Table I Mentors' Demographic and Retention Characteristics

\begin{tabular}{|l|l|l|}
\hline & Characteristics & $\begin{array}{l}\text { Number } \\
\text { (\%) }\end{array}$ \\
\hline Gender & Female & $68(69.4 \%)$ \\
& Male & $30(30.6 \%)$ \\
\hline Coordination group & Mentors with coordination & $24(24.5 \%)$ \\
membership & group membership & \\
& Mentors without coordination & $74(75.5 \%)$ \\
& group membership & \\
\hline Years as mentor & I year & $20(20.4 \%)$ \\
& 2 years & $26(26.5 \%)$ \\
& 3 years & $28(28.6 \%)$ \\
& 4 years & $6(12.2 \%)$ \\
& 5 years & $6(6.1 \%)$ \\
\hline Intention to retention & 6 years & $62(63.3 \%)$ \\
Yor next year & No & $36(36.7 \%)$ \\
\hline
\end{tabular}

complete the questionnaire voluntarily in their own time and return when they had completed it with one week limitation to return with two reminders.

\section{Analysis}

The statistical analysis was performed by the SPSS statistical package program version 20. Descriptive data are expressed as mean and standard deviation (SD) for continuous variables, while the qualitative characteristics are shown as frequencies. To analyze the results of the TCI125 , both crude scores and $t$ scores according to the normative data of the Iranian population were employed. The internal consistency reliability of scales was determined using Cronbach's alpha. Independent $t$-test was used for comparing the means of different aspects of character and temperament based on intention to remain as mentor and membership in coordination group, and Pearson correlation was used for TCI scales and years of mentor retention. For a model of prediction for mentor retention, mentor intention to retention and mentor coordination group membership, we used multinomial regression.

\section{Results}

A descriptive-analytical design was used with a convenience sample of 140 mentors; 98 participants filled out the forms with a response rate of $70 \%$. Retention-related information of participants are shown in Table 1. Cronbach's alphas for the Cloninger Temperament and Character Inventory questionnaire items were 0.73 (for scales NS; 0.76, HA; 0.71, RD; 0.72, P; 0.69, SD; 0.82, C; 0.68, and ST; 0.80). [Table 1 ]

\section{Personality and Mentor Retention}

The variables including subscales "spiritual acceptance" (of ST scale) [ $r=0.24, p=.017]$, "self- forgetfulness" (of ST scale) $[r=0.23, p=.023]$, "shyness" (of HA scale) $[r=0.17$, $\mathrm{p}=.047]$ and mentor retention were weakly correlated, while the subscale "fatigability" (of HA scale) $[\mathrm{r}=-0.20, \mathrm{p}=.047]$ was negatively correlated. Linear regression analysis (with model consisting all personality subscales) was used to predict the relationship between personality subscales and participants' retention of their job as mentor $[R=0.357$, $\mathrm{R} 2=0.191$, Model $\mathrm{F}=3.54, \mathrm{P}=0.039]$. Cooperation scale predicted mentor retention the most with standardized coefficient Beta $=0.255, \mathrm{P}=0.014$.

Multiple logistic regression analysis was used to test not only if the coordination group membership significantly predicted participants' retention as mentors, but also to show how the relationship changes with personality subscales. [Table 2 ]

Table 2 Logistic Regression of Coordination Group Membership and TCl Subscales on Mentor Retention

\begin{tabular}{|c|c|c|c|c|c|c|c|c|}
\hline \multirow[t]{2}{*}{ Variable } & \multirow[t]{2}{*}{ B } & \multirow[t]{2}{*}{ St. Error } & \multirow[t]{2}{*}{ Wald } & \multirow[t]{2}{*}{ df } & \multirow[t]{2}{*}{ Sig. } & \multirow[t]{2}{*}{ Exp. (B) } & \multicolumn{2}{|c|}{ 95\% C.I. for EXP(B) } \\
\hline & & & & & & & Lower & Upper \\
\hline Coordination group membership & 1.095 & 0.607 & 3.247 & I & 0.047 & 2.988 & 1.208 & 9.827 \\
\hline Harm avoidance & 0.325 & 0.516 & 0.397 & I & 0.529 & 1.389 & 0.503 & 3.809 \\
\hline Cooperation & 0.289 & 0.582 & 0.247 & 1 & 0.619 & 1.335 & 0.427 & 4.175 \\
\hline Self-transcendence & $0.06 \mathrm{I}$ & 0.544 & 0.013 & I & 0.910 & 1.063 & 0.366 & 3.085 \\
\hline Reward dependency & 0.049 & 0.527 & 0.009 & 1 & 0.926 & 1.050 & 0.374 & 2.950 \\
\hline Novelty seeking & -.309 & 0.581 & 0.302 & I & 0.582 & 0.727 & 0.233 & 2.267 \\
\hline Self-directedness & -.440 & 0.555 & 0.630 & $\mathrm{I}$ & 0.428 & 0.644 & 0.217 & 1.910 \\
\hline Persistence & -.6 .6 & 0.610 & 0.989 & I & 0.320 & 0.545 & 0.165 & 1.802 \\
\hline
\end{tabular}

Notes: $\mathrm{X} 2=7.638 ; \mathrm{df}=8 ; \mathrm{p}=.022 ;$ Nagelkerke R2=10.7\%; Hosmer and Lemeshow test $(\mathrm{p}=.000)$. 
Table 3 Mean (SD) Score of TCl Subscales According to Coordination Group Membership and Intention to Retention

\begin{tabular}{|c|c|c|c|c|c|c|}
\hline & \multicolumn{2}{|c|}{ Coordination Group Membership } & \multirow[t]{2}{*}{ P-value } & \multicolumn{2}{|c|}{ Intention to Retention } & \multirow[t]{2}{*}{ P-value } \\
\hline & Yes & No & & Yes & No & \\
\hline Novelty seeking & II (3.I) & $10.5(2.3)$ & 0.21 & II.5 (2.I) & $9(2.4)$ & 0.45 \\
\hline Exploratory-excitability & $3.1(1.4)$ & $3.2(1.3)$ & 0.61 & $3.8(1.0)$ & $2.2(I . I)$ & 0.71 \\
\hline Impulsiveness & $2.8(0.81)$ & $2.9(0.85)$ & 0.99 & $2.9(0.82)$ & $2.7(0.86)$ & 0.13 \\
\hline Extravagance & $2.3(0.86)$ & $1.9(0.86)$ & 0.58 & $2.1(0.85)$ & $1.7(0.88)$ & 0.60 \\
\hline Disorderliness & $2.6(0.96)$ & $2.4(1.1)$ & 0.28 & $2.6(1.0)$ & $2.3(1.0)$ & 0.98 \\
\hline Harm avoidance & $9(2.1)$ & $8.4(1.9)$ & 0.63 & $8.7(1.8)$ & $8.2(2.1)$ & 0.05 \\
\hline Anticipatory worry & $2(0.83)$ & $1.9(0.87)$ & 0.22 & $2(0.9)$ & I.8 (0.77) & 0.87 \\
\hline Fear of uncertainty & $1.9(0.97)$ & $2.1(1.0)$ & 0.70 & $2.3(0.9)$ & $1.6(1.0)$ & 0.11 \\
\hline Shyness & $2.9(0.97)$ & $2.4(0.98)$ & 0.72 & $2.5(1.0)$ & $2.6(0.96)$ & 0.85 \\
\hline Fatigability & $2.1(0.7)$ & $1.9(0.86)$ & 0.42 & $1.9(0.78)$ & $2.1(0.88)$ & 0.35 \\
\hline Self-directedness & $10.6(4.0)$ & $10(4.1)$ & 0.48 & $10.7(3.6)$ & $9.3(4.7)$ & 0.04 \\
\hline Responsibility & $1.0(1.4)$ & I.I (I.4) & 0.23 & $1.0(1.4)$ & $1.2(1.5)$ & 0.74 \\
\hline Purposefulness & I.5 (I.0) & $1.8(1.1)$ & 0.52 & $2.0(I . I)$ & $1.3(.95)$ & 0.35 \\
\hline Resourcefulness & $1.7(0.94)$ & $1.4(0.85)$ & 0.80 & $1.6(0.75)$ & $1.3(1.0)$ & 0.01 \\
\hline Self-acceptance & $3.4(1.5)$ & $3.1(1.5)$ & 0.92 & $3.5(1.4)$ & $2.7(1.6)$ & 0.23 \\
\hline Enlightened second nature & $2.9(1.3)$ & $2.5(\mathrm{I} . \mathrm{l})$ & 0.54 & $2.5(\mathrm{I} . \mathrm{l})$ & $2.7(1.3)$ & 0.10 \\
\hline Cooperativeness & $15(2.6)$ & $14.5(2.3)$ & 0.36 & $15.3(2.2)$ & $13.5(2.2)$ & 0.72 \\
\hline Social acceptance & $2.1(0.7)$ & $2.6(0.9)$ & 0.02 & $2.5(0.9)$ & $2.4(0.7)$ & 0.42 \\
\hline Empathy & $4.1(1.0)$ & $3.8(1.0)$ & 0.08 & $4.2(0.8)$ & $3.3(1.2)$ & 0.00 \\
\hline Helpfulness & $3.4(0.65)$ & $3.0(0.85)$ & 0.93 & $3.3(0.7)$ & $2.8(0.9)$ & 0.96 \\
\hline Compassion & $2.0(0.72)$ & $2.2(0.83)$ & 0.34 & $2.0(0.7)$ & $2.2(1.0)$ & 0.01 \\
\hline Pure hearted conscience & $3.3(0.95)$ & $2.8(0.9)$ & 0.23 & $3.1(0.8)$ & $2.6(1.0)$ & 0.00 \\
\hline Reward dependency & $7.2(1.0)$ & $7.3(1.8)$ & 0.49 & $7.6(1.6)$ & $6.6(1.6)$ & 0.66 \\
\hline Sentimentality & $2.7(0.8)$ & $2.7(\mathrm{I} . \mathrm{I})$ & 0.07 & $2.7(1.0)$ & $2.7(1.1)$ & 0.72 \\
\hline Openness to warm communication & $2.0(1.0)$ & $2.4(0.9)$ & 0.60 & $2.4(0.8)$ & $2.2(1.0)$ & 0.20 \\
\hline Attachment & $2.5(0.9)$ & $2.1(1.3)$ & 0.01 & $2.5(1.2)$ & $\mathrm{I} .8(\mathrm{I} .2)$ & 0.63 \\
\hline Self-transcendence & $9.8(3.1)$ & $7.8(3.5)$ & 0.00 & $9.0(3.6)$ & $7.0(3.2)$ & 0.01 \\
\hline Self-forgetfulness & $2.7(1.3)$ & $2.3(1.4)$ & 0.85 & $2.6(1.5)$ & $2.0(1.2)$ & 0.07 \\
\hline Transpersonal identification & $3.5(1.5)$ & $2.9(1.3)$ & 0.11 & $3.4(1.3)$ & $2.6(1.2)$ & 0.49 \\
\hline Spiritual acceptance & $3.5(0.8)$ & $2.5(1.5)$ & 0.00 & $3.0(1.4)$ & $2.4(1.4)$ & 0.51 \\
\hline Persistence & $3.4(0.8)$ & $2.6(1.2)$ & 0.01 & $2.9(1.2)$ & $2.6(I .1)$ & 0.84 \\
\hline
\end{tabular}

\section{Coordination Group Membership and Personality}

The mean values of the TCI scales were compared between participants with and without membership in the coordination group. There was a significant mean difference for self-transcendence and persistence $(t=2.351$, $\mathrm{p}=0.000, \mathrm{t}=2.802, \mathrm{p}=0.001)$ with members of the coordination group having higher scores non-members. Multinomial regression analysis showed among TCI subscales, mentor self-transcendence predicted coordination group membership significantly $[\mathrm{OR}=4.828 \quad(1.336-$ 17.444), $\mathrm{P}=0.016$ ]. [Table 3 ]

\section{Intention to Remain as Mentor and Personality}

The means of the TCI scales, self-transcendence and selfdirectedness were found to be significantly different based on intention to remain as mentor ( $\mathrm{t}=1.672, \mathrm{p}=0.046$ and $\mathrm{t}=2.761, \mathrm{p}=0.011$ ), where participants likely to remain as mentors gained more mean scores. [Table 4 ]

\section{Discussion}

The demand for organizing mentoring programs makes it clear that retaining mentors is vital. Therefore, more attention should be paid to identifying and analyzing turnover 
Table 4 Logistic Regression of Coordination Group Membership and TCI Subscales on Mentor Intention to Retention

\begin{tabular}{|c|c|c|c|c|c|c|c|c|}
\hline \multirow[t]{2}{*}{ Variable } & \multirow[t]{2}{*}{ B } & \multirow[t]{2}{*}{ St. Error } & \multirow[t]{2}{*}{ Wald } & \multirow[t]{2}{*}{ df } & \multirow[t]{2}{*}{ Sig. } & \multirow[t]{2}{*}{ Exp. (B) } & \multicolumn{2}{|c|}{ 95\% C.I. for EXP(B) } \\
\hline & & & & & & & Lower & Upper \\
\hline Coordination group membership & -.091 & 0.645 & 0.020 & I & 0.888 & 0.913 & 0.258 & 3.235 \\
\hline Novelty seeking & 1.720 & 0.620 & 7.689 & I & 0.006 & 5.583 & 1.656 & 18.826 \\
\hline Harm avoidance & -.176 & 0.500 & 0.124 & 1 & 0.725 & 0.839 & 0.315 & 2.234 \\
\hline Self-directedness & 1.665 & 0.711 & 5.475 & $\mathrm{I}$ & 0.019 & 5.284 & 1.310 & 21.309 \\
\hline Cooperation & 0.206 & 0.590 & 0.121 & 1 & 0.728 & 1.228 & 0.386 & 3.908 \\
\hline Reward dependency & 0.597 & 0.515 & 1.344 & 1 & 0.246 & 1.816 & 0.662 & 4.982 \\
\hline Self-transcendence & -.515 & 0.675 & 0.580 & I & 0.446 & 0.598 & 0.159 & 2.246 \\
\hline Persistence & 0.526 & 0.595 & $0.78 I$ & I & 0.377 & 1.691 & 0.527 & 5.424 \\
\hline
\end{tabular}

Notes: $X 2=7.638 ; \mathrm{df}=8 ; \mathrm{p}=.022 ;$ Nagelkerke R2=10.7\%; Hosmer and Lemeshow test $(p=.000)$.

intentions by mentors and managing them to decrease the turnover rate to the minimum. As part of our study, we evaluated mentor retention from the perspective of mentors who are the best judges for their own retention. Although some studies have explored these factors in the fields of business and volunteering, ${ }^{22,23}$ there is limited literature on the relationship between personality traits and turnover intentions in mentoring.

It has been reported that there is a moderately negative relationship between employee turnover and conscientiousness, extraversion, emotional stability and agreeableness, ${ }^{24}$ while results from other studies have indicated that the subscales "agreeableness" and "conscientiousness" predict volunteer satisfaction. ${ }^{25,26}$ Our results suggest that variables of spiritual acceptance, self-forgetfulness, and empathy have a positive correlation with mentor retention; this finding is in line with previous studies about altruistic motivations and spiritual values. It seems that personal and organizational rewards to be most effective nowadays than spiritual values, ${ }^{27}$ although results from our study suggest that the former outweighs the latter. A possible explanation for this might be that our program was run as a volunteer-based mentoring without any financial support or reward for mentors, and we emphasized spiritual values to evoke a sense of altruism in mentors in order to retain them. It seems paying attention to these values could be effective in mentor retention.

Membership in coordination group is predictor of mentor retention which shows that mentor's involvement in program management and leadership results in a sense of belonging to the group. Connors has introduced the "wise volunteer manager" theory in which a manager can use the understanding about volunteer motivations to choose the reward system for the differently motivated volunteers. One of these motivations is the leverage that mentors may enjoy as members of the coordination group. ${ }^{28}$ It seems possible that the recruitment processes could be able to attract people who were likely to follow managerial initiatives and controls. ${ }^{29}$ In our study, mentors who participated in the program as a coordination group member showed significantly much more persistence and self-transcendence. A possible explanation for this is that those who opt for coordination group are almost always perfectionist, ambitious and eager. ${ }^{30}$ These traits are in line with the findings of psychological studies on managers which were found to be less neurotic and agreeable and more extraverted and conscientious. ${ }^{31}$

This study showed more self-directedness scores in coordination group members and mentors who wanted to remain in the program as a mentor. Self-directedness is defined as the ability to regulate and adapt behavior to the demands of a situation to achieve goals. ${ }^{30}$ It is difficult to explain this result, but it might be related to self-directed persons follow objectives and goals. These findings proved that TUMS mentoring program was successful in providing objectives for mentors with high self-directedness and novelty seeking. Objectives could be social networking, altruism or experiencing new challenges. It can thus be suggested that policy maker and educational managers should renew the process of recruitment of mentors, introduce novel situations annually to try to retain their mentors, and identify supportive strategies to improve retention.

If we assume intention to retention as mentors' attitudes and the duration of mentor retention as their action, it seems that personality traits of mentors like high novelty seeking and self-directedness associated with their attitudes but not with their actions. A possible explanation for this might be that although 
mentors' attitudes are under the influence of personality; the effects of environmental factors on the duration of mentor retention are more prominent.

The findings reported here are specific to this program with its specific design, and generalization across all programs is not possible. To solve this limitation, researchers may examine the various predictors within different contexts. This study was a descriptiveanalytical design. It is likely, therefore, to suffer from the fact that results may vary with time. To address this, it is recommended that future studies consider studying mentor turnover intentions from a longitudinal perspective.

One of the strengths of this study was that only a single mentoring program with an acceptable response rate was used, which helped reduce variability due to environmental factors. Personality traits account for only $20 \%$ of mentor retention prediction. Therefore, approximately $80 \%$ remained unexplained, suggesting the need to add additional variables to future studies. Furthermore, it is worth saying that one of the limitations of this research was that the environmental factors not included in this study; therefore, their influence on mentor retention remains to investigate. It is suggested that considering managers and planners' concerns on mentor retention improves the recognition of the current situation, help design, and offer suitable mentoring programs. In future study, the findings with regard to gaining mentorship programs and the extent to which the identified factors inhibit and motivate mentors could compared for ones with different background characteristics and experiences. Future studies should consider the associations of other aspects of program environment such as mentor involvement in program management, mentor empowerment, and program characteristics.

\section{Conclusions}

According to findings the increased mentor's attitudes to retain in program may therefore be explained by an increase in mentors' self-directedness and noveltyseeking traits. Program managers should renew the program goals and introduce novel situations every year to make desire to keep mentors. Since membership in the management group of the program was predictor of mentor retention, we suggest that recruitment processes attract people who are likely to follow managerial initiatives and controls as mentors. It is suggested that considering managers and planners' concerns on mentor retention improves the recognition of the current situation, help design, and offer suitable mentoring programs with regards to personality traits of mentors.

\section{Data Sharing Statement}

The data analyzed during the current study are not publicly available but are available from the corresponding author upon (reasonable) request.

\section{Acknowledgments}

The authors extend their gratitude to all participants for their frank and honest contribution.

\section{Author Contributions}

All authors made substantial contribution to conception and design, acquisition of data, or analysis and interpretation of data; took part in drafting the article or revising it critically for important intellectual content; gave final approval of the version to be published.

\section{Funding}

No funding.

\section{Disclosure}

The authors report no conflicts of interest in this work.

\section{References}

1. Frei E, Stamm M, Buddeberg-Fischer B. Mentoring programs for medical students - a review of the PubMed literature 2000-2008. BMC Med Educ. 2010;10:32.

2. Eby LT, Allen TD, Hoffman BJ, et al. An interdisciplinary meta-analysis of the potential antecedents, correlates, and consequences of protege perceptions of mentoring. Psychol Bull. 2013;139 (2):441-476.

3. GM G. Mentoring medical students in academic emergency medicine. Acad Emerg Med. 2004;11:1351-1357.

4. Ragins BR, Scandura TA. Burden or blessing? Expected costs and benefits of being a mentor. J Organ Behav. 1999;20(4):493-509.

5. Grossman JB, Rhodes JE. The test of time: predictors and effects of duration in youth mentoring relationships. Am J Community Psychol. 2002;30(2):199-219.

6. Barrick MR, Mount MK, Judge TA. Personality and performance at the beginning of the new millennium: what do we know and where do we go next? Int $J$ Sel Assess. 2001;9(1-2):9-30.

7. Weberg D. Transformational leadership and staff retention: an evidence review with implications for healthcare systems. Nurs Adm $Q$ 2010;34(3):246-258.

8. Hong LC, Kaur S. A relationship between organizational climate, employee personality and intention to leave. Int Rev Bus Res Papers. 2008;4(3):1-10.

9. Sandars J, Patel R, Steele H, McAreavey M. Developmental student support in undergraduate medical education: AMEE guide no. 92. Med Teach. 2014;36(12):1015-1026. 
10. Maghbouli N, Moghadas F, Babaei L, Beigy M. The association of temperament and character of mentors/mentees with satisfying formal mentoring of first-year medical students. Thrita. 2017;6(1):e46241.

11. Crew LR. Personality and mentoring: stepping off on the right foot. J Contin Educ Nurs. 2016;47(5):201-203.

12. Eby LT, McManus SE, Simon SA, Russell JE. The protege's perspective regarding negative mentoring experiences: the development of a taxonomy. J Vocat Behav. 2000;57(1):1-21.

13. Bozionelos N. Mentoring provided: relation to mentor's career success, personality, and mentoring received. J Vocat Behav. 2004;64(1):24-46.

14. Abdolalizadeh P, Pourhassan S, Gandomkar R, Heidari F, Sohrabpour AA. Dual peer mentoring program for undergraduate medical students: exploring the perceptions of mentors and mentees. Med J Islam Repub Iran. 2017;31:2.

15. Ghahramani S, Seddigh F, Jahromi ART, et al. Mentoring medical students by their peers, three years' experience at Shiraz Medical School. J Adv Med Educ Professionalism. 2019;7(3):156.

16. Asefzadeh S, Javadi H, Sharifi M. Mentorship at Qazvin Medical School: A Pilot Study in Iran. 2004.

17. Taqavi H, Khaghanizadeh M, Ebadi A. Prediction of academic skills in $\mathrm{Ph}$. D. students based on mentoring at medical sciences universities in Iran. Int J Behav Sci. 2018;12(3):132-140.

18. Cloninger CR, Svrakic DM, Przybeck TR. A psychobiological model of temperament and character. Arch Gen Psychiatry. 1993;50 (12):975-990.

19. Cloninger CR. The science of well-being: an integrated approach to mental health and its disorders. World Psychiatry. 2006;5(2):71.

20. Kaviani H, Pourahmad M. Validation of Temperament and Character Inventory (TCI) in Iranian Sample: Normative Data. 2005.
21. Kijima N, Tanaka E, Suzuki N, Higuchi H, Kitamura T. Reliability and validity of the Japanese version of the temperament and character inventory. Psychol Rep. 2000;86(3):1050-1058.

22. Gumussoy CA. The effect of five-factor model of personality traits on turnover intention among information technology (IT) professionals. AJIT-e. 2016;7(22):7.

23. Bandura A. Self-efficacy: toward a unifying theory of behavioral change. Psychol Rev. 1977;84(2):191.

24. Sarwar A, Hameed S, Aftab H. Study to explore the impact of personality traits on employee turnover in public and private sector. Middle-East J Sci Res. 2013;16(9):1249-1254.

25. Jabari N, Boroujerdi S, Ghaeini S, Abdollahi F, Karimi G. Big-five personality traits predict sport volunteer satisfaction. World Appl Sci J. 2012;19(4):445-450.

26. Milovanovic I. Big-five personality traits, job satisfaction, and turnover intention: a heuristic model for hospital nurses in Japan. Int J Sci Eng Res. 2017;8(2):267-275.

27. Nienaber R, Bussin M, Henn C. The relationship between personality types and reward preferences. Acta Commercii. 2011;2011(Special issue 1):56-79.

28. Connors TD. The Volunteer Management Handbook: Leadership Strategies for Success. 235. John Wiley \& Sons; 2011.

29. Judeh M. Selected personality traits and intent to leave: a field study in insurance corporations. Int Bus Res. 2012;5(5):88.

30. Aluja A, Blanch A. The five and seven factors personality models: differences and similitude between the TCI-R, NEO-FFI-R and ZKPQ-50-CC. Span J Psychol. 2011;14(2):659-666.

31. Furnham A, Crump J. Personality and management level: traits that differentiate leadership levels. Psychology. 2015;6(05):549.
Journal of Multidisciplinary Healthcare

\section{Publish your work in this journal}

The Journal of Multidisciplinary Healthcare is an international, peerreviewed open-access journal that aims to represent and publish research in healthcare areas delivered by practitioners of different disciplines. This includes studies and reviews conducted by multidisciplinary teams as well as research which evaluates the results or conduct of such teams or healthcare processes in general. The journal covers a very wide range of areas and welcomes submissions from practitioners at all levels, from all over the world. The manuscript management system is completely online and includes a very quick and fair peer-review system. Visit http://www.dovepress.com/testimonials. php to read real quotes from published authors. 